\title{
Impact of Television Commercials on Purchasing Behaviour of Masses
}

\author{
Nidhi Rani ${ }^{1}$, Dr. Vikas Sharma ${ }^{2}$ \\ ${ }^{1}$ Research Scholar, OPJS University, Churu, Rajasthan, India \\ ${ }^{2}$ Research Guide, Assistant Professor, NIMS University, Jaipur, India
}

\begin{abstract}
In present day world, television has already become an integral part of life of masses. It is indeed a true fact that various media spread awareness but television advertisements plays a significant role in buying behaviour of people. Advertisement telecasted on television, has ability to combine the visual and audio communications and has capability to affect its target audiences. Thus, this makes advertisements an important medium to make people aware of any product. In light of this the present study was undertaken to measure the impact of television commercials on purchasing behaviour of viewers. A questionnaire was prepared to meet out the objective. The responses by the consumers of the questionnaire were complied into tables. For examining variables, percentage analysis was used. The outcome of the research revealed that adults have strong belief that television commercial has considerably influenced their buying behaviours. Finally some finding, limitations, conclusions and suggestion has been written in this paper.
\end{abstract}

Keywords: Television commercials, purchasing behaviour, significance of T. V. Advertisements.

\section{Introduction}

The process of advertising evolved in ancient times. Different societies used symbols, and pictorial signs to attract their product consumers. For many centuries, these methods were used for the promotion of products. After being successful, this phenomenon gained more strength for promotional purposes. In present day world, advertisements have become one of the major sources of communicational tool between the manufacturer and the user of the products.

One of the major concerns of manufacturing companies is to get the knowledge of consumer's reaction about their product so that their responses can be used to enhance their product and sales. A manufacturing company cannot imagine to be well known brand until they invests in promotional activities, for which consumer market have been dominating through advertisements. Advertising is a proven tool for marketers to affect the performance of their products and their easily adaptation among masses. This useful tool, advertising, is multidimensional and another form of publicity. Advertisements are meant for the masses and people relate themselves with this medium. In simple terms, advertising is an announcement regarding the launch of a product, service or idea through the usage of basically the most popular mass media. Best medium is selected based on its popularity and the one which has maximum reach. Television remains the most effective medium for reaching today's customers and it also is most efficient for introducing people to brands. Advertising through Television allows marketers to show and tell a wide audience about business, product, or service. Television appeals to the literate as well as the illiterate and this is one feature of TV that makes it unique and different from other mediums.

In India, television started functioning as a state owned medium in 1959, went commercial in 1976 and transformed into colour in 1982. Over a longer period of time, the TV set has become a permanent fixture in all upper and middle class households, and it is not uncommon even in the poorer society of urban areas and rural households (Shah \& D'Souza, 2008). It is also proven that visual memories are the strongest memories which make television advertising an effective way in making consumers aware of the existence, characteristics of new products and condition the mind of a potential consumer to take final purchase decision.

\section{Literature Review}

The reviews of the following have enabled the way, to delightfully explore the topic. The past researches act as guidance for the researcher and form the basis for the new researches in any field. These help in finding the gaps in the area of knowledge and provide insight to work on the topic. So, it is essential for the researcher to go through the details of the work undertaken by the researchers in the past. The researcher came across the numerous literature such as advertising influence on consumer behaviour; product purchase process and decision making; children and teenagers' behaviour; lifestyle and consumption; rural and urban consumers.

Greater television viewership is associated with more requests for advertised products. Children from high parental education level reduce the reliance on advertising. TV advertising has greatest effect on younger children than on older children (Robertson \& Rossiter, 1977).

Advertising is to create understanding, strong belief, and selection of product or services. The most affecting theory in marketing and advertising research is attitude-towards-theadvertisement. However, the thinking that is formed towards the commercials help in influencing consumer's attitudes and perception toward the brand until their purchase intent (Goldsmith \& Lafferty, 2002)

Advertisement also plays an important role in affecting the purchase decision for a product. Socio-economic factors such as sex, age, education, occupation and income influence the brand selection of consumers and encourage them to choose 


\section{International Journal of Science and Research (IJSR) ISSN (Online): 2319-7064 \\ Index Copernicus Value (2013): 6.14 | Impact Factor (2014): 5.611}

a specific brand. The study suggested that advertisements must bring out superiority of the product over other brands besides being attractive, influencing and informative (Ravichandran \& Narayanarajan, 2004).

There is a direct relation between attitude towards advertisement and attitude towards product. Customers trust on advertisements till they buy the product. After that they may be satisfied or dissatisfied with the product. Advertisements are double edged weapon due to the fact that advertisements are bound to create positive attitude if claims of advertisements correspond with the features of a product and vice versa (Alexander, 2005).

The study of Fam and Waller (2008) analysed consumers' attitude towards television commercials in Mumbai. In India, the liking and disliking of TV commercials is attributed to general values, family values and religions adherence so the marketers should note that culture plays an important role in consumer perspective and attitude.

TV advertising helps the consumers in improving the choice of product during shopping after discussing with their family. They also viewed TV advertisements as time savers during shopping. The informative factors such as price, quality and suggested use of items advertised improve the educational value of an advertisement and make the consumers aware of prevailing prices (Kotwal et al., 2008).

\section{Research Methodology}

\subsection{Objective}

1) The position of subject of how commercials on television influence purchasing decisions of masses.

2) Study of the subject of how TV advertisements changed the living standards of consumers.

Table 1: Distribution of respondents by gender

\begin{tabular}{|l|c|c|}
\hline Gender & No. of respondents & Total percentage \\
\hline Male & 113 & 50.22 \\
\hline Female & 112 & 49.78 \\
\hline Total & 225 & 100 \\
\hline
\end{tabular}

Source: Primary Data

Gender plays a vital role which influences the buying behaviour of masses. Table 1 above revealed that buyers of the products are almost evenly distributed among both gender, with the number of males marginally higher than that of female. This may suggest gender neutrality in the consumption of the products.

Table 2: Respondent's age distribution

\begin{tabular}{|l|c|c|}
\hline Age (in years) & No. of respondents & Total percentage \\
\hline Under 20 & 87 & 38.67 \\
\hline $21-50$ & 110 & 48.89 \\
\hline Above 50 & 28 & 12.44 \\
\hline Total & 225 & 100 \\
\hline
\end{tabular}

Source: Primary Data

Table 2 shows the respondents age range is divided into 3 groups. Respondents falling into the age group of under 20 years were 38.67 percent and the category from $21-50$ years

\subsection{Sampling Technique}

For the analysis of objectives, random sampling method was adopted. 250 questionnaires were circulated in national capital region. The questionnaire was developed with a motive to seek information on purchasing behaviour of consumers with respect to impact of television commercials.

\subsection{Data Source}

The data used for this analysis were collected from basically two sources and these sources are Primary source and Secondary source. However, the major data for the study were obtained by using structured questionnaire. The respondents were selected randomly at each of the locations while keeping in mind to cover the opinion of urban and rural population of national capital region. However, two hundred and twenty five (225) of the questionnaire representing $90 \%$ of the total was responded to. The secondary data that were also of great assistance was extracted from the journals and articles available in various public libraries.

\subsection{Analysis of Data}

Both descriptive and inferential statistics were used in analyzing the data collected. The responses by the consumers to some items of the questionnaire were complied into tables according to the main variables being examined. Percentage analysis was used in examining variables such as consumer brand preference, awareness by television commercials etc.

\section{Analysis and Interpretation}

Various social and economic parameters of interest were examined to bring the salient characteristics of the respondents.

has represented 48.89 percent. Respondents of above 50 years of age were given 12.44 percent of the total.

Table 3: Respondent's area of residence

\begin{tabular}{|l|c|c|}
\hline Area of Residence & No. of respondents & Total percentage \\
\hline Urban & 129 & 57.33 \\
\hline Rural & 96 & 42.67 \\
\hline Total & 225 & 100 \\
\hline
\end{tabular}

Source: Primary Data

Residential background of masses is assumed to have significant effect on their buying behaviour. Therefore, 129 urban representatives have been selected which constituted 57.33 percent of the total sample, whereas, 96 rural respondents has given their representation in the survey which is 42.67 percent of the total data.

Table 4: Occupation of respondents

\begin{tabular}{|l|c|c|}
\hline Occupation & No. of respondents & Total percentage \\
\hline Employed & 119 & 52.89 \\
\hline Un-employed & 49 & 21.78 \\
\hline Others & 57 & 25.33 \\
\hline Total & 225 & 100 \\
\hline
\end{tabular}

Source: Primary Data 


\section{International Journal of Science and Research (IJSR) \\ ISSN (Online): 2319-7064 \\ Index Copernicus Value (2013): 6.14 | Impact Factor (2014): 5.611}

Data was also collected on the basis of occupation of respondents. Table 4 shows that occupations of respondents were divided into three sections. Most of the respondents were working that comprised of 52.89 percent of the total

Table 5: Annual income of respondents

\begin{tabular}{|l|c|c|}
\hline Annual Income(Rs.) & No. of respondents & Total percentage \\
\hline $0-1,00,000$ & 67 & 29.78 \\
\hline $1,00,000-5,00,000$ & 108 & 48.00 \\
\hline Above $5,00,000$ & 50 & 22.22 \\
\hline Total & 225 & 100 \\
\hline
\end{tabular}

Source: Primary Data

Table 5 shows the annual household income of the respondents. 29.78 percent respondent's annual income was between $0-1,00,000.48 .00$ percent of the total respondents were in the income group of 1,00,000-5,00,000 and rest of the respondents 22.22 percent were in the income group of more than 5,00,000. data. 21.78 percent of the respondents fall under unemployed category. This group includes household women, students and children.

\subsection{Role of television advertisement in selling products}

Advertising can help companies develop consumer's awareness to an unmet need or introduce a product that consumers may see as valuable. This influence is often present when new products enter the market. Customer awareness is often low for these items until companies promote them and attempt to drive customer demand through advertising. The influence of TV advertisements in selling products varies significantly on the basis of following variables of the respondents.

Table 6: TV advertisements influence on the basis of Gender of respondents

\begin{tabular}{|c|c|c|c|c|c|c|}
\hline Response & Male & Percentage & Female & Percentage & Total & Total percentage \\
\hline Yes & 59 & 52.21 & 61 & 54.47 & 120 & 53.33 \\
\hline Sometimes & 35 & 30.97 & 33 & 29.46 & 68 & 30.22 \\
\hline No & 19 & 16.81 & 18 & 16.07 & 37 & 16.45 \\
\hline Total & 113 & 100 & 112 & 100 & 225 & 100 \\
\hline
\end{tabular}

Seeing the role of advertising in selling products, most subjects $(53.33 \%)$ stated that advertising plays an important role in selling products, $(52.21 \%$ male, $54.47 \%$ women $)$. Of all respondents $(30.22 \%)$ reported that sometimes advertising plays an important role in selling products of which $(30.97 \%$ male, $29.46 \%$ women). Only $(16.45 \%)$ did not believe that advertising plays an important role in selling products.

Table 7: TV advertisements influence on the basis of Age of respondents

\begin{tabular}{|l|c|c|c|c|c|c|c|}
\hline Response & Below 20 Years & $\%$ & $21-50$ Years & $\%$ & Above 50 Years & $\%$ & Total \\
\hline Yes & 49 & 56.33 & 67 & 60.91 & 16 & 57.14 & 132 \\
\hline Sometimes & 31 & 35.63 & 34 & 30.91 & 9 & 32.14 & 74 \\
\hline No & 7 & 8.04 & 9 & 8.18 & 3 & 10.72 & 19 \\
\hline Total & 87 & 100 & 110 & 100 & 28 & 100 & 225 \\
\hline
\end{tabular}

On the basis of age of respondents, young people under 20 years $(56.33 \%)$ believe that advertising plays an important role in selling products. Respondents between 21-50 years $(60.91 \%)$ also support the same statement about TV advertisements. Moreover, people above 50 years $(57.14 \%)$ also agree to it.

Table 8: TV advertisements influence on the basis of Area of Residence of respondents

\begin{tabular}{|l|c|c|c|c|c|c|}
\hline Response & Urban & Percentage & Rural & Percentage & Total & Total percentage \\
\hline Yes & 71 & 55.04 & 59 & 61.45 & 130 & 57.78 \\
\hline Sometimes & 49 & 37.98 & 23 & 23.96 & 72 & 32.00 \\
\hline No & 9 & 6.98 & 14 & 14.59 & 23 & 10.22 \\
\hline Total & 129 & 100 & 96 & 100 & 225 & 100 \\
\hline
\end{tabular}

The analysis of result clearly shows that in Urban (55.04\%) products. In addition, rural counterpart (61.45\%) seems to be believe that TV advertisements influence the sale of in favour of above statement.

Table 9: TV advertisements influence on the basis of Occupation of respondents

\begin{tabular}{|l|c|c|c|c|c|c|c|}
\hline Response & Employed & $\%$ & Unemployed & $\%$ & Others & $\%$ & Total \\
\hline Yes & 79 & 66.38 & 27 & 55.10 & 29 & 50.88 & 135 \\
\hline Sometimes & 33 & 27.74 & 13 & 26.54 & 19 & 33.33 & 65 \\
\hline No & 7 & 5.88 & 9 & 18.36 & 9 & 15.79 & 25 \\
\hline Total & 119 & 100 & 49 & 100 & 57 & 100 & 225 \\
\hline
\end{tabular}

On the basis of occupation of respondents, those who agree that advertising plays an important role in selling products are employed like intellectual, officials etc. (66.38\%), unemployed like household women and students (55.10\%) and others including businessmen, entrepreneurs $(50.88 \%)$. Respondents who don't believe at all in advertising are group 


\section{International Journal of Science and Research (IJSR) \\ ISSN (Online): 2319-7064 \\ Index Copernicus Value (2013): 6.14 | Impact Factor (2014): 5.611}

of employed (5.88\%), unemployed (18.36\%) and other $(15.79 \%)$. Thus, on the basis of survey and the analysis of data collected, it clearly shows that commercials telecasted on television affects the sale of products and its frequency of sale and also influences the purchasing decision of masses.

\subsection{Role of television advertisement on end-user's life style}

It has been observed that, fashion, life style and trends are the primary motivations to buy a particular brand. TV commercials affect the lifestyle of consumers. Exposure to TV has influenced the people and has made them more conscious about their health and living standards. Due to these, TV commercial affect the decision of buying branded products by masses.
Table 10: Buying branded products on the basis of Gender of respondents

\begin{tabular}{|l|c|c|c|c|c|c|}
\hline $\begin{array}{l}\text { Respons } \\
e\end{array}$ & $\begin{array}{c}\text { Mal } \\
e\end{array}$ & $\begin{array}{c}\text { Percenta } \\
\text { ge }\end{array}$ & $\begin{array}{c}\text { Fema } \\
\text { le }\end{array}$ & $\begin{array}{c}\text { Percenta } \\
\text { ge }\end{array}$ & $\begin{array}{c}\text { Tot } \\
\text { al }\end{array}$ & $\begin{array}{c}\text { Total } \\
\text { percenta } \\
\text { ge }\end{array}$ \\
\hline Yes & 49 & 43.36 & 67 & 59.83 & 116 & 51.56 \\
\hline $\begin{array}{l}\text { Someti } \\
\text { mes }\end{array}$ & 47 & 41.59 & 35 & 31.25 & 82 & 36.44 \\
\hline No & 17 & 15.05 & 10 & 8.92 & 27 & 12.00 \\
\hline Total & 113 & 100 & 112 & 100 & 225 & 100 \\
\hline
\end{tabular}

On the basis of above table, most respondents $(51.56 \%)$ used to buy branded products, of which $(43.36 \%$ male $59.83 \%$ women). Of the respondents $(36.44 \%)$ say they sometimes used to buy branded products of which $(41.59 \%$ male $31.25 \%$ women). Only $12.00 \%$ of subjects surveyed say they never buy branded products ( $15.05 \%$ male $8.92 \%$ women).

Table 11: Buying branded products on the basis of Age of respondents

\begin{tabular}{|l|c|c|c|c|c|c|c|}
\hline Response & Below 20 Years & $\%$ & $21-50$ Years & $\%$ & Above 50 Years & $\%$ & Total \\
\hline Yes & 51 & 58.62 & 66 & 60.00 & 6 & 21.42 & 123 \\
\hline Sometimes & 20 & 22.98 & 31 & 28.18 & 17 & 60.72 & 68 \\
\hline No & 16 & 18.39 & 13 & 11.82 & 5 & 17.86 & 34 \\
\hline Total & 87 & 100 & 110 & 100 & 28 & 100 & 225 \\
\hline
\end{tabular}

Regarding the age, young people less than 20 years $(58.62 \%)$ and those between $21-50$ years $(60.00 \%)$ say they buy branded products. People above 50 years $(60.72 \%)$ say they sometimes buy branded products. Those who never buy branded products are people under 20 years $(18.39 \%)$ with those between $21-50$ years $(11.82 \%)$.

Table 12: Buying branded products on the basis of Occupation of respondents

\begin{tabular}{|l|c|c|c|c|c|c|c|}
\hline Response & Employed & $\%$ & Unemployed & $\%$ & Others & $\%$ & Total \\
\hline Yes & 73 & 61.34 & 25 & 51.02 & 33 & 57.89 & 131 \\
\hline Sometimes & 35 & 29.41 & 14 & 28.58 & 17 & 29.83 & 66 \\
\hline No & 11 & 9.25 & 10 & 20.40 & 7 & 12.28 & 28 \\
\hline Total & 119 & 100 & 49 & 100 & 57 & 100 & 225 \\
\hline
\end{tabular}

On the basis of occupation of respondents, those who buy branded products are employed like intellectual, officials etc. $(61.34 \%)$, unemployed like household women and students $(51.02 \%)$ and others including businessmen, entrepreneurs $(57.89 \%)$. Respondents who sometimes buy branded products from the group of employed (29.41\%) and unemployed $(28.58 \%)$ and those respondents who never buy branded products are employed $(9.25 \%)$, unemployed $(20.40 \%)$ and others $(12.28 \%)$.

Table 13: Buying branded products on the basis of Income of respondents

\begin{tabular}{|c|c|c|c|c|c|c|c|}
\hline Response & Less than 1 Lac & $\%$ & 1Lac-5Lac & $\%$ & Above 5Lac & $\%$ & Total \\
\hline Yes & 9 & 13.43 & 62 & 57.40 & 31 & 62.00 & 102 \\
\hline Sometimes & 12 & 17.92 & 27 & 25.00 & 13 & 26.00 & 52 \\
\hline No & 46 & 68.65 & 19 & 17.60 & 6 & 12.00 & 71 \\
\hline Total & 67 & 100 & 108 & 100 & 50 & 100 & 225 \\
\hline
\end{tabular}

Seeing the role of household income of respondents in buying branded products, most subjects $(62.00 \%)$ whose annual income is above 5lac, prefer to choose branded products. Respondents whose annual income falls between 1lac-5lac, (57.40\%) also agreed that they buy branded products. Only $(10.42 \%)$ did not believe that advertising plays an important role in selling products. Those respondents who never prefer to buy branded products have annual income between $0-1$ lac $(68.65 \%)$.

Thus, on the basis of above mentioned variables, it is interpreted most of the respondents buy branded products. They get awareness and knowledge about the features of the branded products from TV advertisements so TV advertising has certainly affected their life style.

\section{Findings and Suggestions}

On the basis of above study an attempt has been made to provide empirical findings which have emerged from the overall analysis of impact of television commercials on purchasing behaviour of masses on the basis of certain demographic variables. The effort has also been made to find how the television commercials have changed the living standards of consumers.

The study reveals that the male and female differ with regard to desire for the TV advertised products. Females were found desiring more of the TV advertised products in comparison to the males. Adults have more desire to engage themselves in 


\section{International Journal of Science and Research (IJSR) \\ ISSN (Online): 2319-7064 \\ Index Copernicus Value (2013): 6.14 | Impact Factor (2014): 5.611}

buying TV advertised products. On the whole teenagers are influenced to buy the TV advertised products, as compared with those who are above 50 years.

Another finding from the above study is that the females crave to buy branded products to enhance their lifestyle. Also, adults seem to be more interested in process of buying branded products. This parameter was found more acceptable by the teenagers. Another revelation of the research connotes that the buyers having annual household income more than 5 lakh, accept that buying branded products and services which are advertised on television helps them to enhance their living standard.

TV advertisements affect the buying behaviour of teenagers, therefore the advertisers should make an attempt in influencing the teens not only as influencers of purchase decision but also retain them as their future consumers. Additional features can be added into their products on timely basis and publish its benefits through television commercials. Advertisements influence, either positively or negatively, so a little extra social concern by marketer can add to the betterment of society in general and of their positive image in particular, building strong brands in long run. Also, the finding suggests that successful marketing is based on correctly representing customer life styles and making products relevant to their lives.

\section{Conclusion}

The study shows that television commercials play an important role on the buying behaviour of masses. The efforts have also been made to provide workable suggestions to the advertisers and the marketers in this regard. Most of consumers are interested in buying branded products which helps them to improve their lifestyle. It has been observed that annual household income plays an important place in buying decision. Very important to mention is the fact that the television advertising influences the buying decision of earning buyers. Advertising research styles have involved and advanced, partly through the influence of improved technology and access to advanced theories and methods.

Another finding of the study is that the adults irrespective of their gender and area of residence strongly consider that TV advertisements have impact on their mind and the exposure to TV advertisements have not only enhanced their involvement in purchasing but has resulted in increasing their frequency of purchase.

\section{References}

[1] Bovee, C. L. \& Arens, W. F., Contemporary Advertising, 5th Edition, Irwin Professional Publishing, 1994.

[2] Brand, J. E., \& Greenberg, B. S., Commercials in the classroom: the impact of channel one advertising, Journal of Advertising Research, 34, No. 1, pp. 19-25, 1994.

[3] Dhanabhakyam, M. \& Geetha, S., Ethics in advertisements and its impact. Indian Journal of Marketing, 36, No. 8, pp. 22-39, 2006.
[4] Dubey, J. \& Patel, R. P., Ads that work with youth. Indian Management, 43, No. 10, pp. 68-74, 2004.

[5] Kapoor, D. C., Marketing and Sales Management, 1st Ed. New Delhi: S. Chand \& Company Ltd, 2004.

[6] Kavitha, G., A study on the effectiveness of the advertising techniques used in the personal care segment of women consumers. Indian Journal of Marketing, 36, No. 8, pp. 12-16, 2006.

[7] Kotwal, N., Gupta, N. \& Devi, A., Impact of T.V. advertisements on buying pattern of adolescent girls. Journal of Social Science, 16, No. 1, pp. 51-55, 2008.

[8] Kotler, P., Marketing Management. $11^{\text {th }}$ Ed. Pearson. New Delhi, 2003.

[9] Morgan, M., Heavy television viewing \& perceived quality of life. Journalism Quarterly, 61, No. 3, pp. 499504, 1984.

[10] Moschis, George, P., Teenagers' responses to retailing stimuli. Journal of Retailing, 54, No. 4, pp. 80-93, 1978.

[11] Saxena, R., Marketing Management. $2^{\text {nd }}$ Edition, New Delhi: Tata Mc Graw Hill, 2005.

[12] Schiffman, L. G. \& Kanuk, L. L., Consumer Behaviour. 5th Edition, New Delhi: Prentice Hall, 1996.

[13] Shah, K. \& D’Souza, A., Advertising and Promotion: An IMC Perspective. New Delhi. Tata Mc Graw Hill Companies

\section{Author Profile}

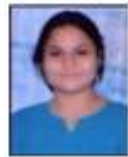

Nidhi Rani is pursuing $\mathrm{PhD}$ (Management), MBA (Finance/Marketing) 2010, B.A. (Management Honours) 2008

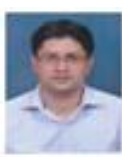

Dr.Vikas Sharma Awarded PhD (Management) Jan.2012, MBA (Finance/Marketing) 2008, B.Com (Accounts/Banking/EAFM) 2006 